\title{
Prolonged Effects of the COVID-19 Pandemic on Sleep Medicine Services Longitudinal Data from the Swedish Sleep Apnea Registry
}

Ludger Grote, MD, PhD ${ }^{a, b, *}$, Jenny Theorell-Haglöw, RN, $\mathrm{PhD}^{\mathrm{c}, \mathrm{d}}$, Martin Ulander, MD, PhD ${ }^{e, f}$, Jan Hedner, MD, PhD ${ }^{a, b}$

\section{KEYWORDS}

- CPAP • Sleep test • Diagnosis • Mandibular advancement device • Polysomnography

- SARS-COV2 • Obstructive sleep apnea • Delivery of health care

\section{KEY POINTS}

- The ongoing COVID-19 pandemic has led to a substantial reduction of sleep medicine services, and the long-term consequences may be considerable.

- Recent data from the National Swedish Sleep Apnea Registry suggested important overall reduction of sleep diagnostic procedures and obstructive sleep apnea (OSA) treatment starts.

- The patients with OSA receiving positive airway pressure therapy may have an advantage relative to those untreated when confronted with a COVID-19 infection.

- New strategies for the management of sleep disorders are needed to overcome the current underdiagnosis and delay of treatment, including patients with OSA who potentially may be on high risk for severe COVID-19.

- Novel clinical routines such as the use of telemedicine may facilitate the recovery of sleep medicine services.

\section{INTRODUCTION}

The COVID-19 pandemic has affected the operation of health care systems. Resources have been shifted from elective care to acute management of severely ill patients affected by life-threatening infections with SARS-COV2. Experiences from virus outbreaks in China, Europe, and America as well as the announcement of a COVID-19 pandemic by the World Health Organization in March 2020 have sparked extensive and wideranging organizational changes in the health care system.

According to current recommendations from several expert organizations, sleep medicine centers are advised to reduce in-laboratory (in-lab) activities such as diagnostic polysomnography or positive airway pressure (PAP) titration, to provide

\footnotetext{
a Center for Sleep and Vigilance Disorders, Sahlgrenska Academy, University of Gothenburg, Medicinaregatan 8B, Box 421, 40530 Gothenburg, Sweden; ${ }^{b}$ Respiratory Department, Sleep Disorders Center, Sahlgrenska University Hospital, 41345 Gothenburg, Sweden; ${ }^{C}$ Department of Medical Sciences, Respiratory, Allergy and Sleep Research, Uppsala University, Akademiska sjukhuset ing 40, 75185 Uppsala, Sweden; ${ }^{d}$ Respiratory Depart-

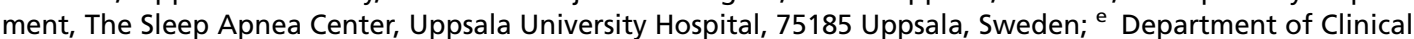
Neurophysiology, Linköping University Hospital, 58185 Linköping, Sweden; ${ }^{\dagger}$ Department of Biomedical and Clinical Sciences, Faculty of Medicine, Linköping University, 58185 Linköping, Sweden

* Corresponding author. Center for Sleep and Vigilance Disorders, Sahlgrenska Academy, University of Gothenburg, Medicinaregatan 8B, Box 421, 40530 Gothenburg, Sweden.

E-mail address: ludger.grote@lungall.gu.se
} 
medical care by distance contact over phone or video calls, and to use telemedicine solutions for the diagnosis and treatment of sleep-disordered breathing. $^{1-6}$

Treatment of sleep-disordered breathing with PAP or noninvasive ventilation during a COVID19 infection has sparked a lively discussion on the pros and cons of the therapy. ${ }^{7,8}$ Noninvasive ventilation has been suggested to cause increased risk for infection particularly among surrounding family members, care givers, or other patients due to aerosol dispersion via the vented mask. ${ }^{9}$ An individual decision may therefore be needed not only in terms of continuation of treatment but also with respect to implementation of various countermeasures (nonvented masks with filters, self-isolation, opening of windows, protection of care givers and other patients). ${ }^{2-4}$

In this review the authors highlight important aspects for a possible association between sleepdisordered breathing, in particular OSA, and COVID-19 and the influence of the COVID-19 pandemic on sleep medicine services. They present the first quantitative analysis on the change of OSA management during 2020 based on data from a Swedish national registry.

\section{SLEEP-DISORDERED BREATHING AS A RISK FACTOR FOR COVID-19 INFECTIONS AND WORSE OUTCOME}

OSA is a prevalent and chronic disease, ${ }^{10}$ and many patients with OSA suffer from cardiometabolic comorbidities. ${ }^{11}$ Interestingly, risk factors for sleep apnea (male gender, higher age, obesity, hypertension, ischemic heart disease, arrhythmia, and diabetes mellitus) correspond to the identified risk factors for worse outcome following severe COVID-19 infections. ${ }^{12}$ The direct impact of sleep apnea on COVID-19 infection outcome remains to be elucidated, but the coincidence of those risk factors suggests that patients with OSA may face an overall increased risk for severe COVID-19 infections and that they may benefit from ongoing therapy if confronted with a COVID-19 infection. ${ }^{13}$

Indeed, several retrospective studies support this hypothesis. A register-based study from Korea including 36,350 patients with chronic respiratory disease and 85,675 controls identified OSA as a risk factor for COVID-19 infection but not for mortality. ${ }^{14}$ In addition, a Finish study performed in 445 individuals diagnosed with COVID-19 identified an increased risk for hospitalization in those with previously diagnosed OSA $(n=38) .{ }^{13}$ Fifty percent of the individuals were hospitalized due to severe COVID19 , which corresponded to an almost 3-fold risk increase (adjusted odds ratio [OR] 2.98, $P=.0048$ ). In the same paper, the investigators performed a meta-analysis of all studies published so far and identified OSA as a risk factor in the models adjusted for age and sex (OR 2.36, 95\% confidence interval [Cl] 1.14-4.95), but the increased risk was no longer significant after control for body mass index (OR 1.55, 95\% Cl 0.88-2.72). Further, a local US-based registry study identified $6.3 \%$ patients with OSA among 9405 patients with COVID-19 compared with a $0.3 \%$ OSA prevalence in the reference material. ${ }^{15}$ For patients with OSA, the adjusted OR was $1.65(95 \% \mathrm{Cl} 1.36-2.02)$ for COVID-19-related hospitalization and 1.98 (95\% Cl 1.63-2.37) for COVID-19-related respiratory failure when compared with non-OSA controls. ${ }^{15}$ In contrast, another study from a large hospitalbased registry identified no association between an OSA diagnosis and COVID-19-related outcome. $^{16}$

Further evidence comes from a recent prospective, questionnaire-based study investigating 320 subjects referred to hospital with a COVID-19 infection. ${ }^{17}$ An increased risk for worse clinical outcome in terms of need for intensive care unit treatment, oxygen supply, or delayed recovery over time was observed in subjects with a history of loud snoring and an elevated risk of OSA according to the Berlin questionnaire score. Although OSA was not assessed by means of an objective sleep test and only a subgroup (61\%) had polymerase chain reaction (PCR)-verified COVID-19, these data suggest that OSA-related factors may play a role in the development of a complicated COVID-19 infection. ${ }^{17}$

In summary, several studies have identified OSA as a potential independent risk factor for severe COVID-19 infections. The exact effect size is difficult to determine due to the high prevalence of comorbidities, in particular obesity, metabolic, and cardiovascular disease. Further prospective studies may benefit from objective assessment of OSA intensity and nocturnal hypoxia as well as a rigorous mapping of comorbidities in both cases and controls.

\section{INFLUENCE OF THE COVID-19 PANDEMIC ON SLEEP MEDICINE SERVICES Existing Evidence}

Several studies have explored the changes of sleep medicine services worldwide. One of the first studies, performed in Europe, explored the change in clinical practice observed in the European Sleep Apnea Database network. ${ }^{18}$ The impact of the COVID-19 pandemic on the management of patients with OSA was assessed by a questionnaire answered by 40 sleep centers in 15 European countries at the time of the first 
lockdown (March/April 2020). Sleep medicine services were dramatically reduced, and staffing levels were decreased to $25 \% / 19 \%$ for physicians/nurses and technicians, respectively, when compared with prepandemic baseline. However, a substantial difference in staffing levels between European regions was identified (Fig. 1). Sleepdisordered breathing diagnosis by in-lab polysomnography/home sleep testing was reduced from 93\%/88\% before COVID-19 to 20\%/33\%, respectively (Fig. 2). In-lab PAP titration was stopped at $72 \%$ of sleep centers, whereas it was still ongoing in $18 \%$ (Fig. 3). Follow-up by phone or video calls were performed by $75 \%$ of the centers but only $25 \%$ allowed for a physical meeting with the patient. At that time of the pandemic, telemedicinebased service had been initiated at some clinics and was performed in only one-third of centers. The data suggest a substantial close-down of sleep medicine services around Europe following the first wave of the COVID-19 pandemic. New strategies such as telemedicine-based practice seemed to be insufficiently exploited.

These results are further supported by several studies investigating the change of sleep medicine practice during the pandemic by means of questionnaires (Table 1). The most comprehensive study so far included 297 American Academy of Sleep Medicine-associated sleep centers located predominantly in the United States and in Canada. ${ }^{19}$ The lockdown of activities was even more pronounced with greater than $90 \%$ reduction of in-lab diagnostic and therapeutic procedures. Mitigation strategies were applied with less

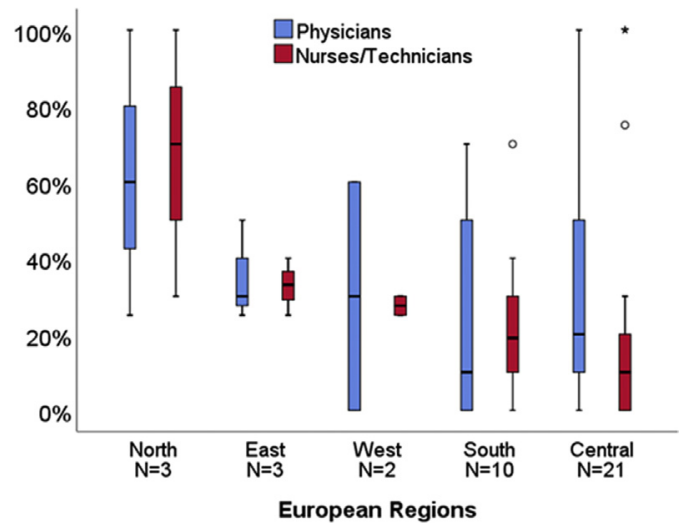

Fig. 1. Staffing in sleep medicine services (in \%) during the COVID-19 pandemic in comparison to regular service (corresponding to $100 \%$ ) in various European regions. (Data reported in Grote L, McNicholas WT, Hedner J; ESADA collaborators. Sleep apnoea management in Europe during the COVID-19 pandemic: data from the European Sleep Apnoea Database (ESADA). Eur Respir J. 2020 Jun 18;55(6):2001323.) extensive mask fitting procedures, PCR testing before visits, or a change to home sleep testing. ${ }^{1,3}$ The picture of a worldwide reduction of activities is further completed by a study from China. ${ }^{20}$ In 56 centers spread out over the country, sleep medicine services were reduced with almost $90 \%$ during the first wave of the pandemic. Subsequently, the activities recovered during summer 2020 to an approximately $50 \%$ level when compared with prepandemic baseline. Further local, regional, and national surveys may have been performed without publication in international journals, but such estimates are usually based on qualitative point assessments. There is an obvious lack of longitudinal and quantitative patient data following the dynamics of the pandemic, which prompted a specific analysis of data from the national Swedish Sleep Apnea Registry (SESAR).

\section{Novel Quantitative Data from the Swedish Sleep Apnea Registry}

SESAR is one out of the 100 national quality registries in Sweden and was started in 2010. SESAR collects patient data from sleep centers involved in the different aspects of sleep apnea management: diagnosis, treatment, and follow-up. In 2019 , data from 23,636 unselected patient visits have been manually entered by 35 sleep centers across Sweden. ${ }^{22}$ The data were obtained at the end of the diagnostic procedure and at the start of the 2 main treatment modalities-PAP and mandibular advancement devices (MAD). A total of 7623 follow-up visits were reported mainly related to PAP therapy $(n=6625)$. The overall

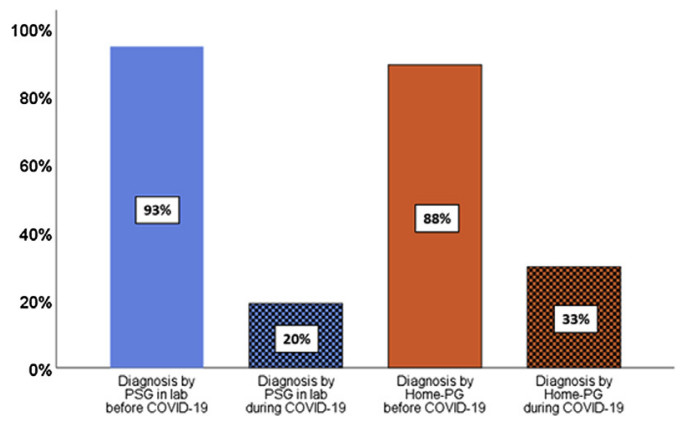

Fig. 2. Changes in the routine of diagnostic procedures during the COVID-19 pandemic demonstrating the marked reduction in both in-laboratory polysomnography (PSG) and ambulatory cardiorespiratory polygraphy (PG). Data are presented as percentage of centers reporting PSG or home-PG use. (Data reported in Grote L, McNicholas WT, Hedner J; ESADA collaborators. Sleep apnoea management in Europe during the COVID-19 pandemic: data from the European Sleep Apnoea Database (ESADA). Eur Respir J. 2020 Jun 18;55(6):2001323.) 


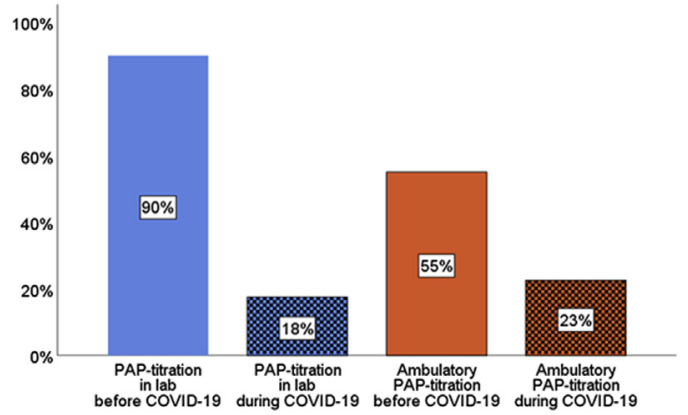

Fig. 3. Changes in the routine of PAP treatment initiation for patients with sleep apnea during the COVID19 pandemic demonstrating the marked reduction in both in-laboratory and ambulatory initiation. Data are presented as percentage of centers reporting in laboratory or ambulatory PAP titration. (Data reported in Grote L, McNicholas WT, Hedner J; ESADA collaborators. Sleep apnoea management in Europe during the COVID-19 pandemic: data from the European Sleep Apnoea Database (ESADA). Eur Respir J. 2020 Jun 18;55(6):2001323.)

national coverage of sleep apnea services has been calculated to exceed $60 \%$ for diagnostic procedures and PAP starts and approximately $20 \%$ for MAD. Clinically relevant results of the registry are publicly available on the registry webpage (www.sesar.se/statistik), which illustrates between-centre comparisons of patient characteristics, waiting times, and treatment outcomes (eg, adherence to PAP, mandibular advancement for $M A D$, proportion of initiated weight reduction therapy in obese patients with OSA).

For the purpose of the current analysis the authors compiled data on patient recruitment during the period March to December 2020 and compared with results from an identical time window of the 2 preceding years (March-December 2018/2019). The mean number of patients registered each month during 2018/19 was calculated and used as a baseline to calculate and plot the change from baseline during year 2020 .

Although there were fewer restrictions related to COVID-19 in the Swedish society, the access to routine health service was significantly reduced mainly in hospitals. As most of the sleep medicine services are centralized at the regional hospitals, access to sleep tests or PAP treatment starts was substantially reduced in those units. In addition, many patients did not show up for scheduled visits due to a perceived increased risk for virus infection. Also, people with common cold symptoms, which are prevalent in Sweden during autumn and winter, were instructed to self-quarantine.

Data from the SESAR registry show a sharp decline in sleep apnea services throughout the entire time window during 2020 (Fig. 4). Compared with baseline from 2018/2019, sleep diagnostic procedures and PAP titrations declined by $50 \%$ before the summer period 2020. After summer, when the virus spreading in the Swedish society was relatively low, some activities recovered very slowly. Subsequently, it was mainly home titration of PAP treatment that fully recovered despite a second wave of the pandemic. Even higher infection rates during November and December 2020 did not change the recovery of PAP titrations. On the contrary, the treatment start of oral devices (MAD) declined even during the second half of the year without any signs of recovery. Further detailed analysis of patient characteristics may be warranted to fully understand the potential selection and prioritization process at the different sleep centers reporting to the SESAR registry.

\section{Reopening of Sleep Medicine Services During the Pandemic}

The data listed earlier clearly demonstrate a large impact of the COVID-19 pandemic on sleep medicine services in many areas of the world. Several important findings need to be pointed out. First, sleep medicine service has been substantially reduced by $50 \%$ to $90 \%$ during the first 10 to 12 months of the global COVID-19 pandemic. Second, in-house procedures, including supervised polysomnography or in-lab PAP titrations, are performed in small scale or not at all or only in a very limited fashion in highly selected patient groups. This change in practice may not fully apply to those countries where home sleep testing and automated PAP titration have been performed even before the pandemic. Third, initiation of PAP treatment of sleep-disordered breathing is significantly reduced and may have recovered at least in some countries. This may in part be the results of a medical prioritization in sleep medicine centers. Fourth, the full potential of mitigation strategies, including telemedicine approaches for diagnosis, treatment initiation, or follow-up of patients with sleepdisordered breathing, has not been studied in more detail. It is anticipated that the use of these new technologies may be introduced much faster during the long-term phases of the pandemic. ${ }^{3}$ It needs to be acknowledged that many questions regarding the advantages and potential disadvantages of a wide telemedicine practice in sleep medicine remain to be fully understood.

\section{CLINICAL APPLICATIONS AND FUTURE RESEARCH}

Our data point toward several clinical implications. First, sleep medicine organizations are 


\begin{tabular}{|c|c|c|c|c|}
\hline Type of Study & Country & $\begin{array}{l}\text { Change in } \\
\text { Diagnostic } \\
\text { Procedures } \\
\text { (\% Change to } \\
\text { Prepandemic } \\
\text { Status) }\end{array}$ & $\begin{array}{l}\text { Change in PAP } \\
\text { Treatment of } \\
\text { OSA (\% Change } \\
\text { to Prepandemic } \\
\text { Status) }\end{array}$ & Comments \\
\hline $\begin{array}{l}\text { Questionnaire } \\
\text { during early } \\
\text { phase of } \\
\text { pandemic }^{18}\end{array}$ & $\begin{array}{l}19 \text { European } \\
\text { countries, } \\
40 \text { centers }\end{array}$ & $-70 \%$ & $-60 \%$ & $\begin{array}{l}\text { Staffing levels } \\
\text { reduced to } 25 \% \\
\text { (physicians) and } \\
19 \% \text { (nurses). } \\
\text { Insufficient use of } \\
\text { telemedicine } \\
\text { technologies }\end{array}$ \\
\hline $\begin{array}{l}\text { Questionnaire, } \\
\text { posted 29th of } \\
\text { April } 2020 \text { to } \\
\text { AASM } \\
\text { members }^{19}\end{array}$ & $\begin{array}{l}297 \text { sleep } \\
\text { centers, 90\% } \\
\text { from the US }\end{array}$ & $\begin{array}{l}>90 \% \text { reduction } \\
\text { in activity: } \\
\text { for PSG by } \\
90.4 \% \text { of } \\
\text { centers, for } \\
\text { HSAT by } \\
60.3 \% \text { of } \\
\text { centers }\end{array}$ & $\begin{array}{l}>90 \% \text { reduction in } \\
\text { PSG-based PAP } \\
\text { titration by } \\
90.4 \% \text { of centers }\end{array}$ & $\begin{array}{l}\text { Reduced mask } \\
\text { fitting procedures. } \\
\text { Mitigation } \\
\text { strategies: } \\
\text { temperature } \\
\text { testing, symptom } \\
\text { evaluation, PCR } \\
\text { testing; }>70 \% \\
\text { virtual patient } \\
\text { visits } \\
\end{array}$ \\
\hline $\begin{array}{l}\text { Questionnaire } \\
\text { during first } 6 \\
\text { mo of } 2020^{20}\end{array}$ & $\begin{array}{l}\text { China, } 56 \\
\text { sleep centers }\end{array}$ & $\begin{array}{l}\text { Initially }-90 \% \text {, } \\
\text { gradual } \\
\text { improvement } \\
\text { to }-40 \%\end{array}$ & $\begin{array}{l}\text { Initially }-95 \% \text {, } \\
\text { gradual } \\
\text { improvement } \\
\text { to }-50 \%\end{array}$ & \\
\hline $\begin{array}{l}\text { Description } \\
\text { of sleep } \\
\text { medicine service } \\
\text { in New York } \\
\text { during the } \\
\text { COVID-19 } \\
\text { outbreak } \\
\text { spring } 2020^{21}\end{array}$ & $\begin{array}{l}\text { New York, } \\
\text { descriptive data }\end{array}$ & $\begin{array}{l}\text { PSG almost } \\
\text { completely } \\
\text { stopped, } \\
\text { HSAT in } \\
\text { selected } \\
\text { cases }\end{array}$ & $\begin{array}{l}\text { In-lab titration } \\
\text { stopped, APAP } \\
\text { used in selected } \\
\text { patients }\end{array}$ & $\begin{array}{l}\text { Use of HEPA } \\
\text { filters and } \\
\text { ventilated rooms } \\
\text { in case of PAP } \\
\text { titration } \\
\text { procedures }\end{array}$ \\
\hline
\end{tabular}

Abbreviations: AASM, American Academy of Sleep Medicine; APAP, autotitrating positive airway pressure; HSAT, home sleep apnea testing; PSG, polysomnography, US, United States.

encouraged to monitor the status of sleep medicine services in their country as we were able to identify substantial regional differences. Second, strategies to maintain "practice as usual" need to be discussed on a regional and national level. Mitigation strategies to provide services should be considered not only in follow-up but also to undiagnosed or not-yet treated patients. Third, there is no current consensus on how to prioritize patients for sleep medicine services. Epidemiologic studies before the pandemic suggest that patients aged 65 years and younger may benefit from OSA treatment in terms of cardiovascular protection. On the other hand, mortality from COVID-19 is elevated in the elderly. Some experts recommend stopping PAP treatment due to aerosol contamination $^{5}$ and others propose high usage of all PAP and bilevel PAP treatment of sleep-disordered breathing and the use of vented masks in case of infection. ${ }^{3}$ Recommendations for both patients and caregivers based on strong scientific evidence should be available at all clinical sites. Indeed, there are now several guidance papers available on both national and international level published by the AASM, ${ }^{1}$ the BTS, ${ }^{2}$ the ERS,${ }^{3}$ the ITS, ${ }^{23}$ the GAVO2, ${ }^{4}$ or on national level. ${ }^{5,6}$

As fewer sleep studies are performed, fewer OSA cases are discovered, but the number of missed cases and the impact of the diagnostic delay cannot be assessed until after the pandemic. Another unresolved issue is how various health care systems will handle the increased inflow of new patients where treatment initialization is warranted once the pandemic is over. The ability of 


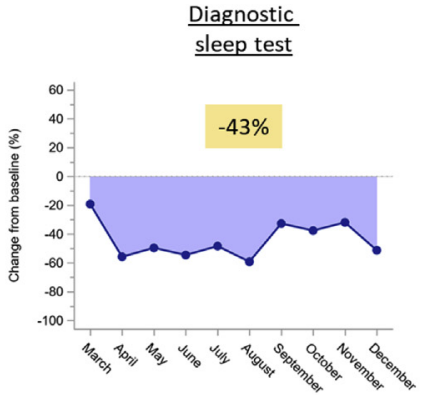

Number of

patients during

2018 and 2019

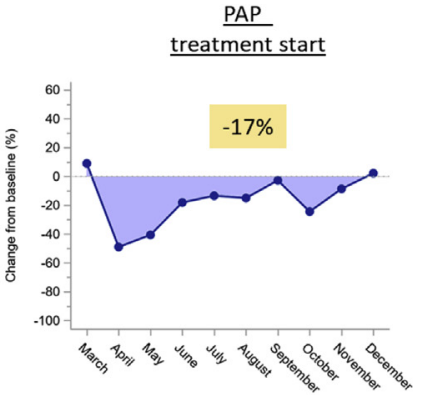

$\mathrm{N}=10188$

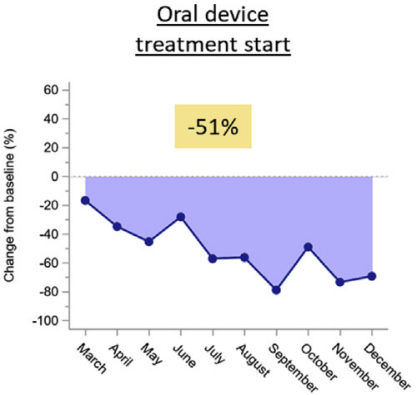

$N=1165$

Fig. 4. Change in activities related to sleep apnea diagnosis and treatment during the first 10 months of the COVID-19 pandemic (March-December 2020). Numbers are based on the reported patient visits for each month (calculated as the change from the mean of 2018/2019). The blue area illustrates the reduction of activities during 2020. Only caregivers reporting during all 3 years are included in the analysis. The total number of patients for the different procedures is stated for 2018 and 2019. Data are presented as percentage change from baseline.

sleep centers to follow-up patients who are already receiving treatment may also be compromised in the long run. Despite several reports on increased PAP use during the pandemic, ${ }^{24,25}$ low adherence is a known issue in PAP therapy, and a shift toward tele-medicine and a reduced access to physical visits treatment may systematically affect adherence. Although there are earlier intervention studies aiming at developing or testing the effects of telemedicine on PAP-adherence, they are typically performed in patients consenting to study participation. Findings from these studies cannot necessarily be generalized to a situation where a shift toward new routines is caused by a global pandemic. Some access to telemedicine interventions, such as video calls with a PAP therapy provider, also require fast Internet access, which may be less available to patients with lower socioeconomical background. It is therefore important to study whether socioeconomic factors may affect access to OSA diagnostics and treatment during and after the pandemic. Finally, the success of vaccination schemes in the general population may rapidly change the situation, and vaccination may be mandatory for at least some of the procedures performed in sleep centers. Many of those questions listed earlier cannot be fully examined until after the pandemic.

\section{SUMMARY}

The authors' findings suggest that the sleep medicine community needs to work together to develop strategies for care of patients with both suspected and established sleep-disordered breathing during major events such as the COVID-19 pandemic. Although personnel may be temporarily recruited to other areas of care, remaining activities need to focus on the recognition of severe cases of SDB and initiate treatment in already identified severe cases. The potential of new technologies allowing for distant monitoring and optimization of treatment may be further used and developed during periods of limited health care resources outside the activities to manage severely affected patients with COVID-19.

\section{CLINICS CARE POINTS}

- Safety measures to avoid spread of the SARSCOV2 virus needs to be implemented when performing sleep diagnostic and therapeutic procedures in sleep centers to protect both personnel and patients. National and international guidance papers have been published.

- There is no firm evidence that untreated sleep apnea may increase the risk for severe COVID19 with adverse outcome. However, successful treatment of severe sleep apnea is likely to be beneficial for patients with OSA when facing an acute SARS-COV2 infection.

- Patients with ongoing PAP therapy at home needs to be informed about the potential increased risk of virus spread for household members by PAP treatment in case of an acute infection. Use of humidifiers during PAP treatment need to be restricted to periods without symptoms of an SARS-COV2 infection.

- The use of telemedicine-based routines for diagnosis, treatment initiation, and follow up of patients with OSA has been implemented in many countries to overcome the partial lockdown of sleep medicine 
procedures. A large proportion of patients may have received equal or even improved sleep medicine services by telemedicine when compared with standard care before the pandemic. However, a subgroup of individuals needs more intensified personal contact with health care professionals. Personalized models of care need to be developed for sleep apnea management in the postpandemic period.

\section{ACKNOWLEDGMENTS}

The authors would like to acknowledge the support of the SESAR registry by Anna Nygren and Monika Hellstrand (register coordinators) and the statistical data analysis performed by Ludwig Andersson (statistician at Registercentrum Västra Götaland, Gothenburg). The authors also express our gratitude to the staff at the participating SESAR centers for continuous data entry during the study period, in particular during the circumstances of the COVID-19 pandemic.

\section{DISCLOSURE}

The authors have no conflict of interest to declare for the content of the submitted manuscript. Outside the submitted work, Dr L. Grote reports grants from Bayer, Philips Respironics Foundation, Resmed Foundation, European Respiratory Society, Itamar Medical, Resmed, and Philips. Dr L. Grote received personal fees for lectures from Respironics, Resmed, Itamar, Fisher \&Paykel and Astra Zeneca. In addition. Dr L. Grote has two patents on sleep apnea therapy licensed.

\section{REFERENCES}

1. American Academy Sleep Medicine. COVID-19 mitigation strategies for sleep clinics and labs 2020. Available at: https://aasm.org/covid-19-resources/.

2. British Thoracic Society. Advice for those seeing patients with obstructive sleep apnoea. Available at: https://www. brit-thoracic.org.uk/about-us/covid-19information-for-the-respiratory-community/.

3. Schiza S, Simonds A, Randerath W, et al. Sleep laboratories reopening and COVID-19: a European perspective. Eur Respir J 2021;57(3):2002722.

4. Gonzalez J, Maisonobe J, Oranger M, et al. GAVO2 procedures (French scientific group on chronic ventilation and oxygen) TITLE: homecare respiratory equipment for patients suspected to be infected with the respiratory virus Covid19 (English version). Version February 2020, French version updated April 2020. Available at: http://splf.fr/gavo2/.
5. Grote L, Albrecht D, Franklin K, et al. Vägledning angående coronavirus (COVID-19) och obstruktiv sömnapné (OSA). 2020. Available at: www.sesar.se/ nyheter.

6. Grote L, Albrecht D, Friberg D, et al. Vägledning vid återstart av utredning och behandling av sömnapné under fortsatt COVID-19-pandemi- 2020. Available at: www.sesar.se/nyheter.

7. Baker JG, Sovani M. Case for continuing community NIV and CPAP during the COVID-19 epidemic. Tho$\operatorname{rax} 2020 ; 75(5): 368$.

8. Barker J, Oyefeso O, Koeckerling D, et al. COVID19: community CPAP and NIV should be stopped unless medically necessary to support life. Thorax 2020;75(5):367.

9. Simonds A, Hanak A, Chatwin M, et al. Evaluation of droplet dispersion during non-invasive ventilation, oxygen therapy, nebuliser treatment and chest physiotherapy in clinical practice: implications for management of pandemic influenza and other airborne infections. Health Technol Assess 2010; 14(46): 131-72.

10. B Benjafield AV, Ayas NT, Eastwood PR, et al. Estimation of the global prevalence and burden of obstructive sleep apnoea: a literature-based analysis. Lancet Respir Med 2019;7(8):687-98.

11. Bonsignore MR, Baiamonte P, Mazzuca E, et al. Obstructive sleep apnea and comorbidities: a dangerous liaison. Multidiscip Respir Med 2019;14: 8.

12. Zhou F, Yu T, Du R, et al. Clinical course and risk factors for mortality of adult inpatients with COVID-19 in Wuhan, China: a retrospective cohort study. Lancet 2020;395(10229): 1054-62.

13. Strausz S, Kiiskinen T, Broberg M, et al. Sleep apnoea is a risk factor for severe COVID-19. BMJ Open Respir Res 2021;8(1):e000845.

14. Oh TK, Song IA. Impact of coronavirus disease2019 on chronic respiratory disease in South Korea: an NHIS COVID-19 database cohort study. BMC Pulm Med 2021;21(1):12.

15. Maas MB, Kim M, Malkani RG, et al. Obstructive sleep apnea and risk of COVID-19 infection, Hospitalization and respiratory failure. Sleep Breath 2020; 1-3. https://doi.org/10.1007/s11325-020-02203-0.

16. Goldstein CA, Rizvydeen M, Conroy DA, et al. The prevalence and impact of pre-existing sleep disorder diagnoses and objective sleep parameters in patients hospitalized for COVID-19. J Clin Sleep Med 2021. https://doi.org/10.5664/jcsm.9132.

17. Peker Y, Celik Y, Arbatli S, et al, OSACOVID-19 Study Collaborators. Effect of high-risk obstructive sleep apnea on clinical outcomes in adults with coronavirus disease 2019: a multicenter, prospective, observational cohort study. Ann Am Thorac Soc 2021. https://doi.org/10.1513/AnnalsATS.20201114090C. 
18. Grote L, McNicholas WT, Hedner J, ESADA collaborators. Sleep apnoea management in Europe during the COVID-19 pandemic: data from the European sleep apnoea database (ESADA). Eur Respir J 2020;55(6):2001323.

19. Johnson KG, Sullivan SS, Nti A, et al. The impact of the COVID-19 pandemic on sleep medicine practices. J Clin Sleep Med 2021;17(1):79-87.

20. Zhang XL, Wang W, Xiao Y. Members of the assembly of sleep disordered breathing of the Chinese thoracic society. Sleep disordered breathing diagnosis and treatment during the COVID-19 pandemic: a nationwide survey in China. Nat Sci Sleep 2021;13:21-30.

21. Thorpy M, Figuera-Losada M, Ahmed I, et al. Management of sleep apnea in New York City during the COVID-19 pandemic. Sleep Med 2020;74: 86-90.
22. Sesar - Swedish sleep apnea registry- annual report 2019 (in Swedish). Available at: www.sesar.se. Accessed January 31, 2021.

23. Insalaco G, Dal Farra F, Braghiroli A, et al. A on behalf of the Italian thoracic society (ITS-AIPO): sleep breathing disorders in the COVID-19 era: Italian thoracic society organizational models for a correct approach to diagnosis and treatment. Respiration 2020;99(8):690-4.

24. Attias D, Pepin JL, Pathak A. Impact of COVID-19 lockdown on adherence to continuous positive airway pressure by obstructive sleep apnoea patients. Eur Respir J 2020;56(1):2001607.

25. Del Campo F, López G, Arroyo CA, et al. Study of the adherence to continuous positive airway pressure treatment in patients with obstructive sleep apnea Syndrome in the confinement during the COVID-19 pandemic. Arch Bronconeumol 2020;56(12):818-9. 